\title{
Left Main Coronary Artery Stenosis Presenting as Syncope with Brugada Type Electrocardiography
}

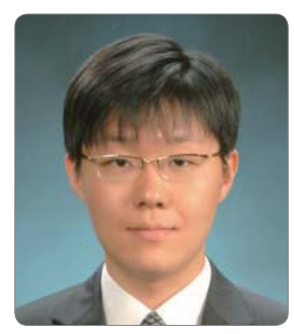

Namkyun Kim

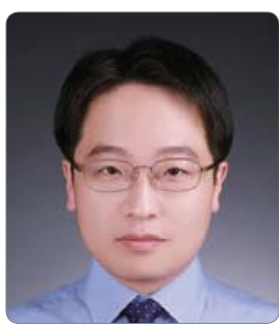

Myung Hwan Bae
Namkyun Kim, MD1, Myung Hwan Bae, MD2,3

${ }^{1}$ Department of Internal Medicine, Kyungpook National University Chilgok Hospital, Daegu, Republic of Korea

${ }^{2}$ School of Medicine, Kyungpook National University, Daegu, Republic of Korea

${ }^{3}$ Department of Internal Medicine, Kyungpook National University Hospital, Daegu, Republic of Korea
Received: January 16, 2018

Accepted: March 9, 2018

Correspondence: Myung Hwan Bae, MD

Department of Internal Medicine, Kyungpook

National University Hospital, Kyungpook Nationa

University School of Medicine, 130 Dongdeok-ro,

Jung-gu, Daegu 41944, Republic of Korea

Tel: +82-53-420-5524, Fax: +82-53-424-6721

E-mail: bae-ttung@hanmail.net

Copyright (C) 2018 The Official Journal of Korean Heart Rhythm Society Editorial Board

\begin{abstract}
A 34-year-old man presented to the outpatient clinic with syncope for 1 minute when he was working. He had no past medical and family history of sudden cardiac death. Electrocardiography (ECG) showed no remarkable findings. Follow-up ECG different from initial ECG was changed to type 1 Brugada ECG pattern. As time goes by, follow-up ECG was changed to type 2 Brugada ECG pattern. Although cause of syncope was assessed as Brugada syndrome, we performed coronary angiography to rule out ischemic heart disease. Coronary angiogram showed significant stenosis in the left main coronary artery (LMCA). Percutaneous coronary intervention with sirolimus-eluting stent was done at LMCA. He has been followed up for 1 year without any events. This is the first case of LMCA as syncope with Brugada type ECG in a young patient and it gives us the lesson that ischemic heart disease should be considered as the cause of syncope with Brugada type ECG.
\end{abstract}

Key Words: - Brugada Syndrome Coronary Artery Disease -Syncopee

\section{A 34-year-old man who had syncope for $1 \mathrm{~min}$ while working} in a sitting position presented to the outpatient clinic of our hospital. He had no relevant medical history. On physical examination, his blood pressure and heart rate were 123/82 $\mathrm{mmHg}$ and 80 beats/min, respectively. He had no family history of sudden cardiac death. Electrocardiography (ECG) showed no remarkable findings. He had no symptoms such as chest pain, dyspnea, or palpitation.

While waiting for the test results, syncope recurred in the emergency room. Routine laboratory test results were normal, except for cardiac troponin, which was slightly elevated at 0.058 $\mathrm{ng} / \mathrm{mL}$. Transthoracic echocardiography showed preserved left ventricular ejection fraction (65\%) with no regional wall motion abnormality. Follow-up ECG showed type 1 Brugada pattern, which was different from the initial ECG (Figure 1A). As the time passed, follow-up ECG was changed to type 2 Brugada ECG pattern (Figure 1B). Although the cause of syncope was assessed as Brugada syndrome, coronary angiography was performed to rule 


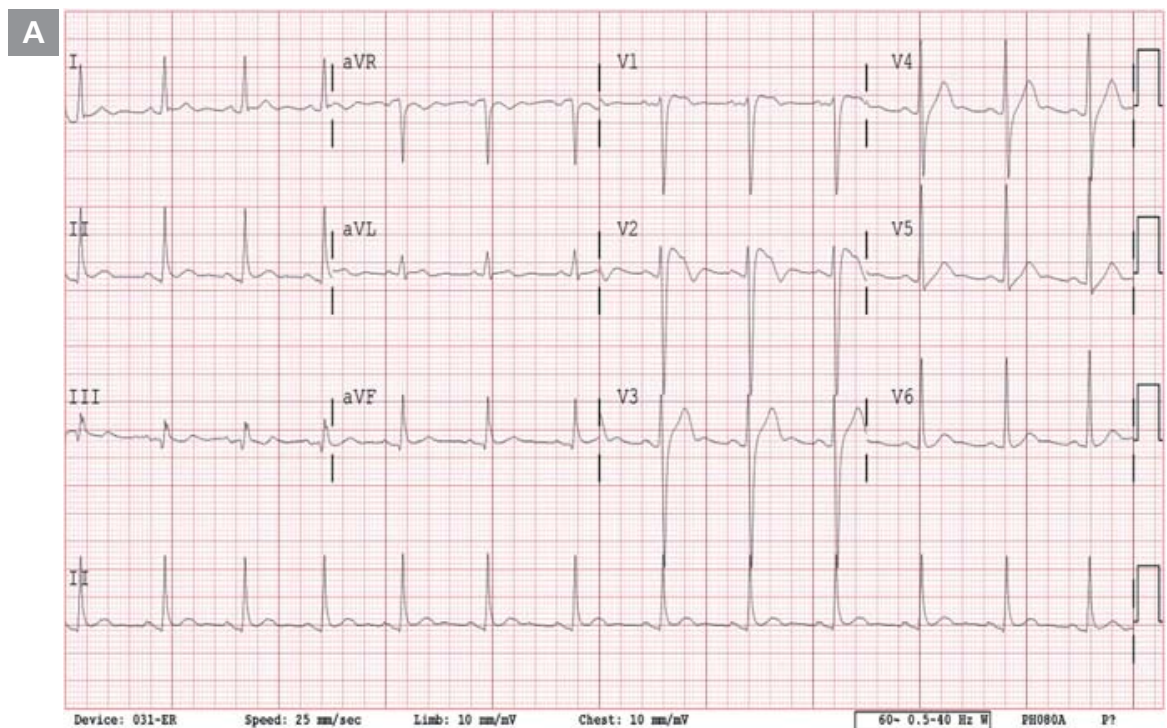

\section{B}

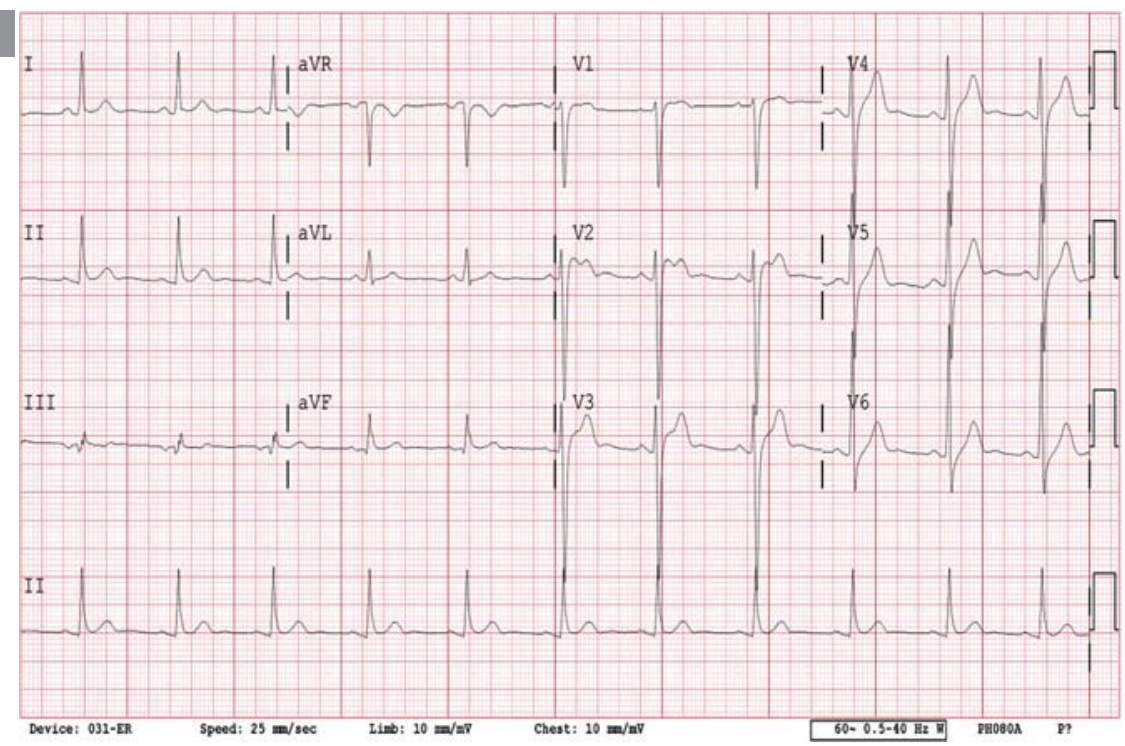

Figure 1. (A), (B) ECG showing type 1 Brugada ECG pattern and type 2 Brugada ECG pattern

out ischemic heart disease. Coronary angiogram showed significant stenosis in the left main coronary artery (LMCA; Figure 2A; Movie 1). Intravascular ultrasound (IVUS) of the LMCA showed lipid-rich necrotic cores with vulnerable plaque (Figure 2B; Movie 1). Percutaneous coronary intervention (PCI) with sirolimus-eluting Orsiro stent was performed at the LMCA. After then, syncope did not recur, and Brugada-type ECG did not appear during the 1-year follow-up period.

Syncope is common and has many possible causes. Previous studies showed that cardiac diseases account for $8.3 \%-23 \%$ among all causes of syncope. ${ }^{1-3}$ Syncope is relatively common in Brugada syndrome with coved- or saddle-back type ST-segment elevation in the right precordial leads (28\%). ${ }^{4}$ The guideline recommends the use of implantable cardioverter defibrillator (ICD) when the cause of syncope is unknown even after sufficient examination in patients with type 1 Brugada syndrome with syncope. 5 In our case, although the patient was asymptomatic for ischemic heart disease, LMCA stenosis was found on examination while evaluating the cause for syncope.

In patients with ischemic heart disease, syncope as initial 


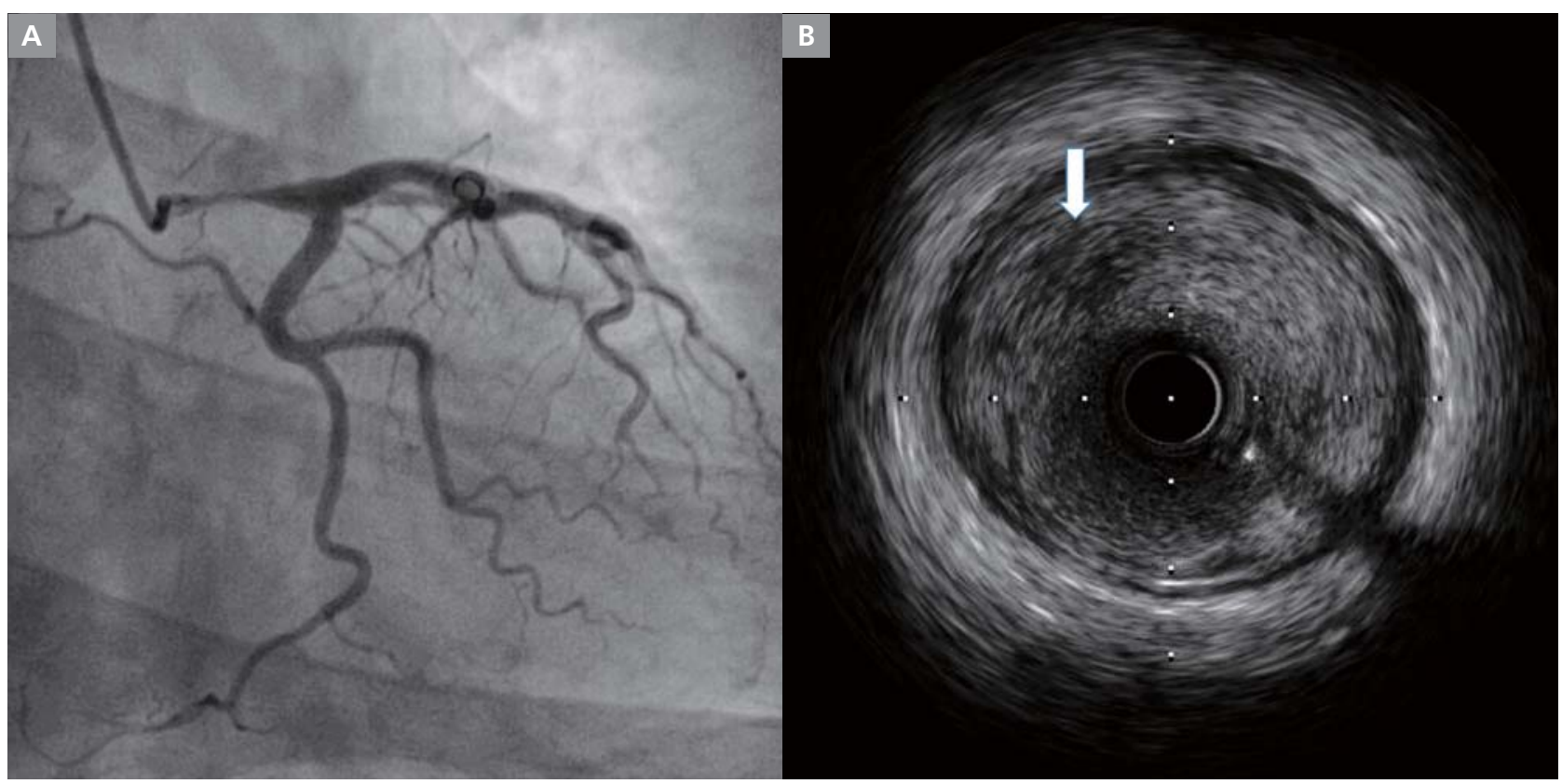

Figure 2. (A) Coronary angiogram showing significant stenosis in the left main coronary artery. (B) Intravascular ultrasound (IVUS) showing lipid-rich necrotic cores (arrow) of vulnerable plaque.

presentation is very rare. ${ }^{6}$ Syncope is usually caused by cerebral hypoperfusion. ${ }^{7}$ In situations where hemodynamic changes may occur, sudden collapse of the coronary artery blood flow may lead to syncope before chest pain has occurred. Therefore, the evaluation for ischemic heart disease in younger patients without typical symptoms, such as chest pain, may be ignored, even if they have a relatively clear cause of syncope.

We speculate that the cause of syncope is likely to be LMCA disease because syncope did not occur after treatment with PCI at LMCA stenosis, and Brugada-type ECG has also not been observed during the 1-year serial follow-up period.

The clinical implication of Brugada-type ECG in this patient is unclear. LMCA hypoperfusion might have caused the Brugada-type ECG change. Alternatively, it might be just a bystander in patient with LMCA, but Brugada syndrome may develop over time. Therefore, long-term follow-up is necessary to determine the clinical significance of Brugada-type ECG in this patient.

This is the first case of LMCA presenting as syncope with Brugada-type ECG in a young patient, and it reminded us to consider ischemic heart disease as the cause of syncope with Brugada type ECG.

\section{Disclosures}

The authors declare no conflict of interest.

\section{References}

1) Alboni P, Brignole M, Menozzi C, Raviele A, Del Rosso A, Dinelli $\mathrm{M}$, Solano A, Bottoni N. Diagnostic value of history in patients with syncope with or without heart disease. J Am Coll Cardiol. 2001;37:1921-1928.

2) Mathias CJ, Deguchi K, Schatz I. Observations on recurrent syncope and presyncope in 641 patients. Lancet. 2001;357:348353.

3) Soteriades ES, Evans JC, Larson MG, Chen MH, Chen L, Benjamin EJ, Levy D. Incidence and prognosis of syncope. N EngIJ Med. 2002;347:878-885.

4) Sacher F, Arsac F, Wilton SB, Derval N, Denis A, de Guillebon M, Ramoul K, Bordachar P, Ritter P, Hocini M, Clémenty J, Jaïs P, Haïssaguerre M. Syncope in Brugada syndrome patients: prevalence, characteristics, and outcome. Heart Rhythm. 2012;9:1272-1279.

5) Priori SG, Wilde AA, Horie M, Cho Y, Behr ER, Berul C, Blom N, 
Brugada J, Chiang CE, Huikuri H, Kannankeril P, Krahn A, Leenhardt A, Moss A, Schwartz PJ, Shimizu W, Tomaselli G, Tracy C. HRS/EHRA/APHRS expert consensus statement on the diagnosis and management of patients with inherited primary arrhythmia syndromes: document endorsed by HRS, EHRA, and APHRS in May 2013 and by ACCF, AHA, PACES, and AEPC in June 2013. Heart Rhythm. 2013;10:1932-1963.

6) Mahajan N, Hollander G, Malik B, Temple B, Thekkoott D, Abrol S, Schulhoff N, Ghosh J, Shani J, Lichstein E. Isolated and significant left main coronary artery disease: demographics, hemodynamics and angiographic features. Angiology. 2006;57:464477.

7) Shen WK, Sheldon RS, Benditt DG, Cohen MI, Forman DE,
Goldberger ZD, Grubb BP, Hamdan MH, Krahn AD, Link MS, Olshansky B, Raj SR, Sandhu RK, Sorajja D, Sun BC, Yancy CW. 2017 ACC/AHA/HRS Guideline for the Evaluation and Management of Patients With Syncope: A Report of the American College of Cardiology/American Heart Association Task Force on Clinical Practice Guidelines, and the Heart Rhythm Society. Circulation. 2017 Aug 1;136:e60-e122.

\section{Supplementary Material}

Movie 1. Intravascular ultrasound (IVUS) of the LMCA showed lipidrich necrotic cores with vulnerable plaque (doi: http://dx.doi.org/10.18501/arrhythmia.2018.003.m001) 